\title{
Devaneio em chamas: Bachelard põe a mão no fogo pelo imaginário
}

\author{
Daydream on fire: Bachelard's burning and imaginary
}

Michèle SATO ${ }^{1}$

Thiago Cury LUIZ²

"O amor é fogo que arde sem se ver"

[Luís Vaz de Camões]

\begin{abstract}
Resumo
Este artigo é fruto das nossas incursões no quilombo Mata Cavalo, zona rural de Nossa Senhora do Livramento-MT, em um dos sete processos formativos que integram a nossa pesquisa de doutorado no Programa de Pós-Graduaçáo em Educação da Universidade Federal de Mato Grosso. O Grupo Pesquisador em Educação Ambiental, Comunicação e Arte (Gpea) lançou mão da fenomenologia de Gaston Bachelard para definir conceitualmente o imaginário do autor a respeito do fogo. Em conjunto, as dinâmicas em grupo, envolvendo estudantes, professoras(es) e moradoras(es) do quilombo, concretizaram-se por meio de recursos comunicacionais e artísticos, a partir dos quais identificamos os elementos do imaginário quilombola sobre o fogo.
\end{abstract}

Palavras-chave: Gaston Bachelard. Fogo. Educação Ambiental. Justiça Climática.

\begin{abstract}
This article is a result of our learning process in Mata Cavalo "quilombo" (descendants of enslaved people), in Nossa Senhora do Livramento's rural zone from the Mato Grosso state, in one of seven formative processes that integrate our $\mathrm{PhD}$ research in Education Postgraduate Programme, at Federal University of Mato Grosso. The Researcher Group in Environmental Education, Communication and Art made use of Gaston Bachelard's phenomenology, which consists conceptually the imaginary of fire element. Simultaneously, the dynamics in group, involving students, teachers and residents from quilombo, were finalized by means of communication and artistic incomes, from which we identified the elements of the quilombola imaginary about fire.
\end{abstract}

Keywords: Gaston Bachelard. Fire. Environmental Education. Climate Justice.

1 Doutora em Ciências, coordenadora do Grupo Pesquisador em Educação Ambiental, Comunicação e Arte (Gpea) e professora titular do Programa de Pós-Graduação em Educação da Universidade Federal de Mato Grosso (UFMT). Avenida Fernando Corrêa da Costa, 2367. Fone: (65) 99687.8727. CEP: 78060-900. E-mail: michelesato@gmail.com.

2 Mestre em Comunicação, doutorando em Educação no Grupo Pesquisador em Educação Ambiental, Comunicação e Arte (Gpea) e professor assistente do Departamento de Comunicação Social da Universidade Federal de Mato Grosso (UFMT). Avenida Fernando Corrêa da Costa, 2367. Fone: (65) 99984.0104. CEP: 78060-900. E-mail: thcluiz@gmail.com.

R. Educ. Públ.

Cuiabá v. 28 n. 69 p. $703-716$ set./dez. 2019 


\section{Aquecendo as ideias}

Uma lareira, um bom vinho e os delírios do fogo sempre aquecem os corpos. O filósofo Gaston Bachelard $(1997,2008)$ buscava aliar estas figuras sensuais, fantasiosas e poéticas ao campo epistemológico e da formação do espírito científico. Nas dualidades da noite e do dia, pulsava um sonido entre new age e rock and roll, ou das imagens criadoras que faziam com que o imaginário tivesse duplo movimento de ressonância e repercussão.

Foi aquecendo este campo poético que o Grupo Pesquisador em Educação Ambiental, Comunicação e Arte (Gpea) ousou afoguear seus momentos investigativos com formativos, na aliança entre a construção das ciências com a vontade de mudar o mundo. Sob o pavio do projeto financiado pela Fundaçáo de Amparo à Pesquisa do Estado de Mato Grosso (Fapemat), a Rede Internacional de Pesquisadores em Justiça Climática e Educação Ambiental (Reaja) trouxe a comunidade de Mata cavalo como centro piroclástico de fazer ciências sem perder a poesia.

Queríamos incendiar ideias, agregando palhas, gravetos e folhas secas para que a combustão em labaredas pudesse comunicar a importância da compreensão sobre o fenômeno climático, essencialmente sobre os desastres e quem seriam os povos mais atingidos. Por certo, os efeitos da crise climática atingirão a todos deste planeta azul, chamado Terra. Contudo, seus efeitos terão escala, proporçáo, magnitude e injustiça de forma bastante diferenciada.

Interessava-nos, assim, conhecer como um dos grupos em situação de vulnerabilidade (quilombo) interpretava o clima. Nossa hipótese era de que se tratava de um assunto desconhecido e, portanto, o processo formativo foi cuidadosamente planejado e essencialmente presente na intervenção da pesquisa.

A formação, entretanto, não é um fósforo que acende o incenso, senão várias faíscas assopradas nas palhas secas, que tornariam as labaredas fluídas, na composição orgânica de fogos em forma de rizomas, sem ter uma cratera emissora de lavas, mas diversos cones, chaminés e câmeras magmáticas que fluíssem em uma epistemologia popular amalgamada pela fenomenologia (BACHELARD, 2008).

Estamos cientes de que não temos controle sobre este fogo, que se lança em várias direçóes, velocidade e até embaixo da água, como linhas de fuga em pleno processo de desterritorializaçáo do fogo. Assim pensavam Deleuze e Guattari (1997) sobre a filosofia: que ela adentrava diversas e amplas dimensóes como a arte, a educação ou a clínica.

Nas chamas da Cartografia do Imaginário (SATO, 2011), nossa proposta optou por um amplo fórum de diálogo de saberes entre a comunidade quilombola 
de Mata Cavalo e o Gpea. Algumas oficinas se relacionaram com os quatro elementos de Bachelard - água, terra, fogo e ar. E incluímos os calores oriundos da justiça climática, educação ambiental, comunicação e arte.

Para cada elemento, as linguagens tocaram a educação ambiental de forma diferenciada, entre os fluxos dos pontos e dos objetivos de cada pesquisador. Neste texto, interessa-nos comentar sobre o fogo, ainda que ele se conecte com os demais elementos. $\mathrm{Na}$ transcriação didática, organizamos os substratos para melhor compreensão, mas a vida não é fragmentada, e pulsa em cada reta, curva, ponto e linhas dos rizomas (DELEUZE, 2002) elementais (BACHELARD, 1997).

\section{Ateando fogo: o incêndio de valores extremos}

Do ponto de vista climático, o pior desastre no território brasileiro está associado ao aumento significativo da temperatura, que trará inúmeros prejuízos de todas as ordens socioambientais. As ondas de calor, a seca, a queimada, a escassez da água, a morte da biodiversidade e essencialmente a emissão de gás carbônico pela queima de florestas principalmente para as atividades destruidoras advindas do agronegócio.

É verdade que o fogo criminoso, que incendeia vastos campos para o desenvolvimento da agricultura, causa danos consideráveis. Além de prejudicar a geração de oxigênio, emitem $\mathrm{CO} 2$ na atmosfera, contribuindo sobremaneira para o aquecimento global e o colapso climático, razão pela qual "[...] o incendiário é o mais dissimulado dos criminosos" (BACHELARD, 2008, p. 21). Em contrapartida, a natureza ígnea viabilizou o aquecimento do corpo, a iluminação, a manipulação de metais, o cozimento e consequente ingestão de nutrientes importantes ao corpo, como os ácidos graxos da carne.

Por isso, a conquista do fogo, presumida pela sua invenção e manejo, é traço importante da evolução da espécie. Não por outro motivo, quando só alguns indivíduos - os mais evoluídos do ponto de vista cognitivo - monopolizavam o saber sobre a geração do fogo, os conflitos se disseminaram. Os agrupamentos mais antigos - a maior parte dos existentes até então -, presos a conhecimentos arcaicos e reconhecendo o valor do fogo, só conseguiam tê-lo consigo pelo furto da matriz. O cenário da guerra de todos contra todos, expressão cunhada por Hobbes n'O Leviatã, é retratada no filme A guerra do fogo (1981), de JeanJacques Annaud.

A ambivalência, característica já levantada por Bachelard em $A$ água e os sonhos (1997), está em voga também na obra $A$ psicanálise do fogo (2008), naquilo 
que o pensador chamará de "[...] sublimação dialética” (2008, p. 149). Ao mesmo tempo em que ele nos remete às lembranças, bem como às profundezas de um rio, tocar a chama interrompe a incursão histórica, conduzindo-nos ao presente pela inconveniência da dor. Assim, o fogo,

Dentre todos os fenômenos, é realmente o único capaz de receber tấo nitidamente as duas valorizaçôes contrárias: o bem e o mal. Ele brilha no Paraíso, abrasa no Inferno. É doçura e tortura. Cozinha e apocalipse. É prazer para a criança sentada ajuizadamente junto à lareira; castiga, no entanto, toda desobediência quando se quer brincar demasiado de perto com suas chamas. O fogo é bem-estar e respeito. É um deus tutelar e terrível, bom e mau. Pode contradizer-se, por isso é um dos princípios de explicação universal. (BACHELARD, 2008, p. 11-12).

Tendo o pressuposto da contrariedade como alicerce das suas proposiçóes, o autor (2008, p. 119-120) reitera que "[...] é pela contradiçáo que se chega mais facilmente à originalidade, e a originalidade é uma das pretensóes dominantes do inconsciente. [...] As contradiçóes acumulam-se para conservarem o valor do fogo". Em resumo, existe "[...] uma intimidade do fogo cuja função será contradizer as aparências do fogo. O que se deixa transparecer é sempre diferente daquilo que em realidade é" (BACHELARD, 2008, p. 120, grifos do autor).

Tendo em vista as técnicas de execução e manutenção do fogo e as interdições que sofremos quando crianças acerca dos seus perigos, a instância ígnea pode ser considerada, na visão bachelardiana, mais um ser social do que natural. Nesse sentido, é possível que as proibiçóes, tal qual o pecado original, conduzam as pessoas na contramão dos conselhos, e as incitam a querer o que não se deve, movimento definido por Bachelard (2008, p. 17) como "[...] desobediência engenhosa”. Temos, aqui, outra ambivalência se desnudando.

Trazendo as vicissitudes do imaginário para o âmbito da ciência e considerando que não é possível dissociar o espírito científico dos devaneios, o desenvolvimento da pesquisa tem na figura do pesquisador alguém que constantemente recorre, mesmo sem notar, à alma primitiva (BACHELARD, 2008). Submetido a uma espécie de hipnose, reação que o elemento fogo tem capacidade de gerar, o investigador, a priori, já não é mais um ser objetivo, meta esta que é meramente uma ideia, não concretude.

Subscrevemos esse ponto de vista: mais do que a vontade, mais do que o impulso vital, a Imaginação é a força mesma 
da produção psíquica. Psiquicamente, somos criados por nosso devaneio. Criados e limitados por nosso devaneio, pois é o devaneio que desenha os últimos confins de nosso espírito. (BACHELARD, 2008, p. 161).

Do ponto de vista técnico, por exemplo, o ser humano primitivo não dispunha das ferramentas e manuseios para inventar o fogo. Prova de que o conhecimento puro, em princípio, inexiste, posto que sem a experiência de forjá-lo pela primeira vez, não há como raciocinar a partir do nada absoluto. Com evidência, portanto, o fogo tem como motivaçáo hipotética a necessidade de calor e todas as ocorrências que ele pode viabilizar, na medida em que entendemos necessidade como um valor vinculado ao que é apetecível.

É preciso, então, pelo instinto - mas não puro e simples - gerar energia artificial. Antes de friccionar pedaços de pau, a humanidade o fazia entre corpos, no ato que se convencionou chamar de sexo. Corpo a corpo em atrito, além de prazer, gera calor. Em tempo e sem mais delongas, o prazer só é consumado na presença de calor.

\section{Combustão às vidas em Mata Cavalo: a fenomenologia do fogo quilombola}

No contexto da pesquisa, tínhamos a hipótese de que os moradores de Mata Cavalo desconheciam o fenômeno climático. Por isso, uma de nossas táticas metodológicas foi planejar um processo formativo subdividido em sete cartografias conceituais: Mudança e Justiça Climática; Narrativa transmídia e Educomunicação; Cartografia da água; Cartografia da terra; Cartografia do fogo; Cartografia do ar; e Cartografia da mandioca.

Este texto busca trazer a reflexão de uma dessas cartografias - o fogo. Por intermédio da vivência pedagógica, inúmeros elementos emergiram: as percepções sobre o fogo e os fenômenos climáticos a ele associados possibilitaram nossa comunicação com os estudantes, professores[as] e membros da comunidade de Mata Cavalo.

Os facilitadores da cartografia iniciam a dinâmica perguntando se os participantes haviam trazido a pedra solicitada no último encontro - qualquer pedra do ambiente de Mata Cavalo. A seguir, convidaram a comunidade presente na Casa da Cultura Quilombola para introduzir o objeto numa bacia cheia d'água. É permitido, a quem preferir, tocar a máo no líquido para sentir e cheirar a água. Esse momento introdutório foi importante para o desfecho da atividade. 
Dando encaminhamento à oficina, é solicitado ao público para se levantar e caminhar pelo ambiente da casa, uma vez que, antes da dinâmica, é importante conhecer o espaço para posteriormente escolher um local e se instalar. Neste momento, um exercício corporal é feito: movimentação, alongamento e respiração, pressupondo geração de energia, surgimento de calor (esfregação das mãos e toque no próprio corpo).

Enquanto objeto buscado pelo olhar, o fogo nos convida ao repouso, ao devaneio de olhos abertos enquanto miramos as chamas. É como se o fogo, agressivo no toque, agisse como um entorpecente, um alucinógeno pronto a colocar quem o avista na rota dos pensamentos fugidios e das investidas sonhadoras. Desse modo, são atribuídos ao fogo valores como velocidade e vivacidade que, por sua vez, simbolizam transformação (BACHELARD, 2008).

No campo científico, essa metamorfose é representada pela transição entre ideia, nomeada por Bachelard de imaginário, e o estudo. O objeto científico só é submetido ao rigor das demonstrações e comprovaçóes se antes for sonhado. $\mathrm{E}$, convenhamos, ainda que não sejam fundamentais, é nas experiências que a imaginação se ancora quando a referência é o fogo.

Assim, é comum encontrarmos no mundo da ciência, no que se refere ao fogo, as evidências de que o seu surgimento se deu pela fricção de dois pedaços de madeira ocasionada pela ação humana. No entanto, há poucas ponderaçóes acerca do que levou, das motivaçóes que circundavam o indivíduo no momento em que a ideia surge. Ainda que repleto de caráter hipotético, uma explicação de feiçóes psicológicas pode contribuir para elucidar o que a ciência é incapaz de realizar.

Tendo isso em vista, o passo seguinte do processo formativo convida os participantes a sincronizarem os movimentos do corpo com sons (o fogo, especialmente o mais arcaico cuja combustão ocorre a partir da madeira, além de calor, também produz barulho). Concomitante, os facilitadores questionam os participantes sobre que som tem o fogo que nos protege, que nos faz bem. $\mathrm{Na}$ sequência, pergunta que som possui o fogo nocivo. Em ambos os casos, os participantes vão produzindo a sonoridade com a boca, mãos e dedos. $\mathrm{Na}$ sensação de alívio pela liberdade em relação ao fogo, outras manifestaçóes são feitas, sem que tenha havido o pronunciamento de palavras. O som característico de comemoraçáo prevaleceu entre os participantes da oficina.

Aqui já fica ensejado o aspecto negativo que a comunidade atribui ao fogo, em consonância com os constantes problemas relacionados à seca (queimadas, falta de água) pelos quais passam os moradores de Mata Cavalo, que, como uma população em situação de vulnerabilidade, sofre mais fortemente os efeitos das mudanças climáticas. 
Como dinâmica seguinte, os facilitadores colocam a música (em vídeo) Barco Negro, de David Mourão-Ferreira e interpretada pela cantora portuguesa Mariza. Eles lembram que a música também foi gravada pelo brasileiro Ney Matogrosso.

De manhã, que medo, que me achasses feia! Acordei, tremendo, deitada n'areia Mas logo os teus olhos disseram que náo E o sol penetrou no meu coração. [bis]

Vi depois, numa rocha, uma cruz,

E o teu barco negro dançava na luz Vi teu braço acenando, entre as velas já soltas Dizem as velhas da praia, que não voltas: São loucas! São loucas!

Eu sei, meu amor, Que nem chegaste a partir, Pois tudo, em meu redor, Me diz qu'estás sempre comigo. [bis]

No vento que lança areia nos vidros; $\mathrm{Na}$ água que canta, no fogo mortiço; No calor do leito, nos bancos vazios; Dentro do meu peito, estás sempre comigo. (MOURÃO-FERREIRA, 1943)

$\mathrm{Na}$ sequência, um dos mediadores propóe uma reflexão sobre o que tem de fogo na música, seja no cenário do show, na letra da música ou no som produzido pela canção. A ideia é ir além do fogo que vimos e sentimos, provando que essa transcendência é exposta na música. O fogo está no corpo, está na madeira, está na sociedade (em manifestaçóes, conflitos).

Com efeito, Gaston Bachelard (2008) vai aliar ao fogo os movimentos das mãos (carícia ritmada) e o canto (suavidade ritmada). Enquanto a música carece de cadência para se tornar um texto em melodia, as máos esquentam, desde que em movimento, aquilo que tocam. O próprio polimento da pedra sucedendo a sua configuração em lascas contrapóe dois tipos de humanidade: um mais agressivo, violento (feiçôes pontiagudas), e outro mais sensível, pacífico (feiçóes curvilíneas, lisas). "De uma forma um tanto paradoxal, diríamos de bom grado 
que a idade da pedra lascada é a idade da pedra maltratada, enquanto a idade da pedra polida é a idade da pedra acariciada" (BACHELARD, 2008, p. 48).

De igual modo, inferimos que no mundo dos devaneios é preciso entregar-se ao afeto, à paciência, que, em ritmo tal como o do polimento das pedras, emergese nas imagens que serão relacionadas ao amor, ao sexo, uma vez que o princípio, como já demonstrado em várias metáforas, é o mesmo.

Não é possível afirmar - e Bachelard não comete tal irresponsabilidade que o raciocínio uniu atrito e calor no sexo e, de imediato, supôs que a mesma fórmula funcionaria na natureza ao friccionar madeiras, numa demonstração de que "[...] se o fogo sai do corpo humano, é porque ele estava antes contido no corpo humano (BACHELARD, 2008, p. 103, grifos do autor). Por isso, no mundo das ambivalências, proposto por Bachelard, "[...] a interiorização do fogo não apenas exalta suas virtudes, como também prepara as mais formais contradições" (BACHELARD, 2008, p. 112).

Mas a imagem, o pensamento que, pela experiência ou de forma automática, converte contato em calor pode ter induzido o ser humano a inventar uma técnica bem-sucedida, sem que houvesse indícios materiais de que fosse dar certo.

[...] Toda tentativa objetiva de produzir o fogo pela fricção é sugerida por experiências íntimas. [...] $\mathrm{O}$ amor é a primeira hipótese científica para a reprodução objetiva do fogo. Prometeu é antes um amante vigoroso do que um filósofo inteligente, e a vingança dos deuses é uma vingança de ciúme. (BACHELARD, 2008, p. 37, grifo do autor).

Para uma compreensão mais ampla do assunto, as facilitadoras exibem dois vídeos sobre o fogo: o trecho introdutório do documentário $A$ origem do fogo: evolução humana e uma cena do filme $A$ guerra do fogo, para que a partir daí os presentes tenham condiçóes de externar o imaginário quilombola sobre o fogo.

Enquanto o documentário apresentou algumas diretrizes sobre o princípio do fogo e a sua importância na história humana, o filme mostrou como o fogo foi concebido nos seus primórdios: um graveto sendo atritado contra outro e, a partir do estopim, alimentando o fogo incipiente com palha. Em cena, duas pessoas submetidas a evoluçóes distintas, uma dominando a técnica de elaboraçáo do fogo, já tendo o corpo pintado (indício de evoluçáo), enquanto o outro, ainda com feições mais animalescas (excesso de pelos), apenas observa, aprende e se encanta, pois sabia que dominar o fogo simbolizava um tipo de poder.

Aseguir, um dos mediadoressugereadinâmicade responderosquestionamentos feitos ao longo da oficina - e outros que possam surgir durante o exercício. 
Porém, as respostas devem ser expressadas por meio de manifestaçóes artísticas: teatro, música, pintura e expressáo corporal. As equipes, com exceção da pintura, além da própria manifestação, devem elaborar um desenho que reitere ou complemente o conteúdo explicitado nos movimentos corporais, na cançáo composta e na peça teatral. Ao final de 40 minutos de elaboração, os quatro grupos expuseram as suas criaçóes e expuseram o imaginário quilombola a respeito do fogo.

O primeiro grupo a se apresentar foi o responsável pela expressão corporal. Uma das participantes foi incendiando jornais em movimentos ritmados e, subsequente, apagando-o. A reboque, a água surge como elemento garantidor da eliminação do fogo, tido como negativo no imaginário do grupo, posto que fora destruído duas vezes (pelo ar e pela água). No desenho, a exposição é de que o fogo destrói e transforma, num ciclo com água e terra. Além disso, a mulher é retratada como figura fundamental do quilombo no que se refere ao elemento que se opóe ao fogo - neste caso, a água. Assim, as mulheres são as maiores prejudicadas pela seca (ausência de água, excesso de calor), já que o ordenamento quilombola ainda relega a elas a elaboração de utensílios, gastronomia, lavagem de roupa e o transporte da água do rio para as casas com vistas ao consumo.

De certa forma, a ideia de sexualização também circunda a culinária, pois só a água quente consegue romper a rigidez de alguns alimentos ou fundir vários produtos para originar outro. A menção ao sexo aparece aqui em quatro níveis: [1] na combustão entre fogo e madeira, gerando energia; [2] no aquecimento da água pelo fogo; [3] na comunhão entre água quente e produto; e [4] na conjugação entre diferentes produtos, formando um novo. Pertinente se faz mencionar que, assim como o sexo é ritual, ritmado, bem como tudo o que é análogo a ele, a culinária, sendo uma metáfora sexual, prescreve rituais, ritmos, calor.

No contato do fogo com o recipiente, do recipiente quente com a água e da água que queima com o alimento, tem-se o receituário para a transformação. Essa combinação - o sexo não seria uma? - gera visuais, odores e paladares que sensibilizam os indivíduos a cercar o banquete. Ocorre, então, um envolvimento entre comida e pessoas, antes, durante e depois do contato ser consumado.

Então, o devaneio é realmente arrebatador e dramático; amplifica o destino humano; une o pequeno ao grande, a lareira ao vulcáo, a vida de uma lenha à vida de um mundo. O ser fascinado ouve o apelo da fogueira. Para ele, a destruição é mais do que uma mudança, é uma renovação. (BACHELARD, 2008, p. 25, grifos do autor). 
No segundo grupo, responsável pela música, enquanto o ritmo remeteu à capoeira - expressáo artística tipicamente africana -, a letra versou sobre as lutas e vitórias da comunidade de Mata Cavalo, em clara menção feita à resistência herdada dos seus antepassados; às festanças dos quilombolas, outra herança do povo africano, repleto em sua cultura de gingado, voz e alegria; às mulheres e suas cacimbas cheias d'água no translado do rio para o uso doméstico. A cançáo é encerrada com um pedido de respeito, pela água, pelo fogo, pela história da comunidade preconizada por seu Antônio Mulato, no ritmo da capoeira.

Quero cantar minha história. Presta atenção, oh meu senhor. No Quilombo Mata Cavalo, Onde a luta começou.

E tem luta e tem vitória. $(4 \mathrm{x})$

$\mathrm{E}$ as mulheres das cacimbas, Que têm garra e tem valor. E também têm as festanças, Que transmitem o seu valor.

Precisamos de respeito, Seja na água ou no calor. Mata Cavalo tem história, Que Seu Mulato começou. (Música composta por moradoras e professoras quilombolas, 2018)

Recorrendo novamente a Bachelard (2008), o estopim para a geração do fogo está presente no sexo e em criaçóes eminentemente humanas, como a música.

Foi, talvez, nesse terno trabalho que o homem aprendeu a cantar. Em todo caso, trata-se de um trabalho evidentemente rítmico, um trabalho que responde ao ritmo do trabalhador, que lhe proporciona belas e múltiplas ressonâncias: o braço que esfrega, as madeiras que gemem, a voz que canta, tudo se une na mesma harmonia, na mesma dinamogenia rítmica; tudo converge para uma mesma esperança, para um objetivo cujo valor se conhece. (BACHELARD, 2008, p. 43-44, grifos do autor). 
No desenho do grupo, foram retratadas as lutas, os grilhóes quebrados e o fogo tomando conta da árvore (queimada), um dos problemas mais recorrentes do quilombo em época de seca. Ainda assim, a resistência, o histórico de lutas do povo quilombola também é retratado pelo fato da árvore, mesmo sofrendo com o fogo (seca/queimada), conseguir se restabelecer e frutificar, numa metáfora da luta, que é constante.

Já a terceira equipe, do teatro, apresentou enredo sobre a violência do fazendeiro, dono da terra, aos trabalhadores que nela labutam, em um movimento de recuperar o passado escravocrata a que foram submetidos os seus antepassados. Essa violência é mostrada por meio da ameaça com o fogo, elemento novamente retratado como nocivo, negativo.

Outra vez vemos a relação do fogo com a água: ela vem como elemento que traz o afago. A terra foi apresentada sob o mesmo aspecto da água, na sua feição positiva. Neste caso, como sinônimo de esperança e luta, já que ela, no imaginário quilombola, está relacionada diretamente à terra, motivo de luta pela garantia do seu território. A flor, fruto da terra e da água, expóe a liberdade (no enredo da peça, a liberdade das mulheres aprisionadas no início da encenação), outra característica muito presente no imaginário quilombola e, por isso, tão recorrente nas manifestaçôes da comunidade. Toda a apresentação foi acompanhada de música (melodia e letra), além do discurso final enaltecendo as lutas e a esperança.

Por fim, a equipe responsável pela pintura trabalhou com tinta guache e colagem. Na cartolina, os integrantes do grupo esboçaram o sol, apresentando-o como guia. Assim, implicitamente, veem no fogo um elemento positivo. Integrando a composição, mãos e pés foram esboçados no intuito de representar o trabalho e as constantes lutas no campo. Como ficou recorrente no imaginário quilombola sobre o fogo, a ambivalência com a água foi inevitável, ilustrada na obra com o rio - elemento muito presente no imaginário acerca da água -, que pressupóe paz e, nesta perspectiva, margeia uma casa de sapê, outra simbologia do quilombo. "Em particular, a água e o fogo permanecem inimigos até no devaneio, e aquele que escuta o regato dificilmente pode compreender o que ouve cantar as chamas: eles não falam a mesma língua" (BACHELARD, 2008, p. 132).

Nos encaminhamentos finais, os facilitadores propuseram um cortejo em torno da Casa da Cultura Quilombola, com cada participante portando uma vela acesa. Ao terminar a procissão, foram convidados a apagar o fogo com um dos outros três elementos: sopro, gota ou poeira.

De acordo com a fundamentação bíblica, do mesmo modo que a água simboliza purificação, o fogo também pode ser entendido assim. No exemplo 
da água, o dilúvio, retaliação de Deus ao caminho impertinente seguido pela humanidade, e o batismo, ritual inaugurado por Cristo, simbolizam a limpeza do espírito. O fogo enquanto elemento de renovação é retratado no livro final da Bíblia, o Apocalipse. Argumento religioso à parte, a ideia de purificaçáo que acompanha o fogo pode ser retratada pela sua capacidade de desodorização.

Essa, em todo caso, é uma das provas mais diretas da purificação. O odor é uma qualidade primitiva, imperiosa, que se impóe pela presença mais hipócrita ou mais importuna. Ele realmente viola a nossa intimidade. O fogo purifica tudo, porque suprime os odores nauseabundos. (BACHELARD, 2008, p. 150151, grifos do autor).

A recorrência da morte é menor em $A$ psicanálise do fogo (2008), numa comparaçáo com a obra $A$ água e os sonhos (1997). O déficit é justificável: enquanto a água tem como metáfora maior o caráter perecível das coisas na coexistência com a vida, o fogo é atrelado a um movimento enérgico, sem ter como destino inadiável o fim absoluto, mas a transformação. Por isso, enquanto a morte na água é solitária, no fogo ela ganha uma dimensão cósmica, de comunhão com o ambiente que com ela queima.

Retomando a dinâmica inicial das pedras, uma parábola bíblica é relatada: um frade peregrino portava pedras. Em cada local que passava, pedia abrigo e comida. A família anfitriã oferecia os ingredientes, enquanto o celibatário, as pedras, que eram "cozidas" junto à sopa. Para Bachelard (2008, p. 24), o fogo não se limita a cozinhar, já que "[...] por uma espécie de prazer de luxo, como sobremesa, o fogo demonstra a sua humanidade".

Ao ir embora, o participante levava a pedra consigo como símbolo do calor (afetividade, do interior, do espírito) da família que seguia com ele na sua caminhada. Isso porque, no entendimento de Gaston Bachelard (2008), as metáforas não são meras idealizações, pois “[...] se convocam e se coordenam mais que as sensaçóes, ao ponto de um espírito poético ser pura e simplesmente uma sintaxe das metáforas" (BACHELARD, 2008, p. 159).

A cartografia é encerrada com a materializaçâo da parábola do frade: cada participante pega uma pedra no balde d'água, desde de que não fosse a sua, e leva para casa o calor do outro, símbolo da comunhão entre existências. "Dito de outro modo, o que passou pela prova do fogo ganhou em homogeneidade, portanto em pureza" (BACHELARD, 2008, p. 151-152). 


\section{O fogo descansa em brasa e cinzas}

A psicanálise do fogo talvez seja a obra mais conhecida de Gaston Bachelard, que ao fazer emergir as analogias com a existência humana, os devaneios dos sonhos e os desejos humanos, consegue atrair atenção de várias áreas do conhecimento. Neste livro, o autor demonstra que a objetividade, requisito tão perseguido e exigido no campo científico, é dissolvido logo de cara, naquilo que Bachelar denomina "[...] sedução primeira" (2008, p. 2). A despeito da aparente posição voltada ao rigor, o cientista, como não poderia ser de outra forma, é conduzido não só pelas amarras dos métodos, mas também pelos sonhos. Assim, este cientista nos apresenta um imaginário repleto de contradiçóes ou, como ele prefere, de ambivalências. No mundo das metáforas, Bachelard investe na sublimação dialética para esboçar o elemento, cujos contrapontos são a sua mais elevada marca.

Dentre tantas analogias, o amor é uma das mais recorrentes. Como ele se dá na relação mínima entre duas pessoas, sempre estará na interação eu-outro, porque os que se amam emitem e recebem luz, trocam energia (fogo) rumo à manutenção do que sentem.

Como é característico da obra desse autor, o elemento da natureza aqui exposto pode ser entendido para além do seu sentido literal. Ao retratar o fogo, Bachelard (2008) nada mais faz do que compreender a existência humana justamente em seu teor dialético, oscilante, seja nas externalidades com outras pessoas, seja nas viagens de si a si mesmo.

No âmbito da emergência climática e do cenário de injustiça que a nova ordem gera, o fogo é compreendido como protagonista de distúrbios no meio ambiente, como na ocorrência de queimadas e nas ocorrências do aquecimento global. Porém, está registrado nas tradiçóes das populaçóes em situação de vulnerabilidade como elemento que viabiliza a culinária, a transitar de geração à geração. Neste caso, identificamos o fogo não como elemento prejudicial, mas algo que fortifica a resistência às agressóes do clima.

$\mathrm{E}$ foi isso que notamos no processo formativo realizado junto à comunidade quilombola de Mata Cavalo. É bem verdade que o fogo foi recorrentemente citado sob o seu aspecto negativo, uma vez que as queimadas, especialmente no período de estiagem (de abril a outubro) castiga Mato Grosso, com destaque à zona rural. Ou seja, o fogo é visto como elemento a ser eliminado. Devido a isso, detectamos que a água é recurso presente no imaginário quilombola pelo viés positivo, tanto por cessar o fogo proveniente de queimadas e secas, como por ser elemento tâo escasso na comunidade e, justamente por isso, valioso. 
Mas há também o fogo da fogueira dos rituais, do fogão que viabiliza a culinária. Há o calor das relaçóes interpessoais no âmbito do quilombo, da batida do tambor no toque da capoeira, da voz que canta o passado de opressão, o presente de lutas e esperanças das populaçôes em situação de vulnerabilidade. Tem calor nos movimentos do corpo, nas expressóes de resistência, na dança como aspecto central da cultura africana.

Assim como em Bachelard, o imaginário quilombola a respeito do fogo é repleto de dialéticas. Em suas vertentes positivas e negativas, o fogo, segundo moradores, professores e estudantes de Mata Cavalo, foi exposto por meio de expressóes artísticas, como teatro, música, pintura e movimento corporal. A arte, mais precisamente a poesia, tão presente nos devaneios do filósofo francês, serviu aos participantes da oficina, que brincaram com fogo sem medo de se queimar.

\section{Referências}

BACHELARD, Gaston. A água e os sonhos. Tradução: Antonio de Pádua Danesi. São Paulo: Martins Fontes, 1997.

BACHELARD, Gaston. A psicanálise do fogo. Tradução: Paulo Neves. 3. ed. São Paulo: Martins Fontes, 2008.

DELEUZE, Gilles; GUATTARI, Félix. O que é filosofia? São Paulo: 34, 1997.

DELEUZE, Gilles. Espinosa: filosofia prática. São Paulo: Escuta, 2002.

SATO, Michèle. Cartografia do imaginário no mundo da pesquisa. In: ABÍLIO, Francisco (org.) Educação ambiental para o semiárido. João Pessoa: EdUFPB, 2011. p. 539-569.

MOURÁO-FERREIRA, David. Barco Negro, 1943. In OLIVA, Osmar P. Travessias do "Barco Negro" - O sequestro da mãe negra. Interdisciplinar. Ano XI, v.25, mai./ago. 2016. Disponível em: <https://seer.ufs.br/index.php/ interdisciplinar/article/view/5749/4753>. Acesso em: 30.ago.2019. 